\title{
LEITURA E TRABALHO DOCENTE NA ESCOLA: ontem e hoje
}

\begin{abstract}
ROSEMARY LAPA OLIVEIRA
Universidade do Estado da Bahia (UNEB). Pós-doutora e Doutora em Educação, Mestre em Linguística. Professora Titular do Departamento de Educação da UNEB - Campus 1 Salvador. Professora do Programa de Pós graduação em Educação e Contemporaneidade. Líder do Grupo de pesquisa e estudo em leitura e contação de histórias GPELCH/UNEB/PPGEDUC e membro de grupos de pesquisa FORMACCE-INFÂNCIA/UNEB. ORCID: 0000-0003-1165-8265.

E-mail: rosy.lapa@gmail.com
\end{abstract}




\section{LEITURA E TRABALHO DOCENTE NA ESCOLA: ontem e hoje}

O presente artigo tem por objetivo provocar uma discussão acerca das ações pedagógicas que envolvem as aulas de leitura no ensino médio das escolas de educação básica no Brasil, focando-se na produção de leitura e como, diante das políticas brasileiras sobre a formação docente, os professores continuam apresentando uma pedagogia da leitura que é obsoleta diante das demandas sociais e não alcança as expectativas dos textos do Governo Federal sobre a formação para o letramento. O percurso de construção do texto considerou um breve apanhado histórico, no qual se historicia a relação que a escola vem mantendo com a leitura, através de evidências documentais e literárias, culminando com dados empíricos de pesquisa realizada em uma escola de ensino médio da capital baiana no momento em que o livro didático é implantado no ensino médio. Assim, foram trazidos depoimentos de docentes e discentes relatando suas experiências com o ensino aprendizagem de leitura na escola. Os resultados apontam que, embora tenha havido uma melhora nos resultados de avaliações externas com relação à leitura, muito esforço ainda precisará ser dispensado para que a formação do leitor considere a autonomia, a situacionalidade e a intercriticidade, adjetivos considerados primordiais para a constituição de sujeitos de leitura.

Palavras-chave: Leitura. Políticas Educacionais. Formação Docente. Letramento. Ensino.

\section{LECTURA Y TRABAJO DOCENTE EN LA ESCUELA: ayer y hoy}

El presente artículo tiene por objetivo provocar una discusión acerca de las acciones pedagógicas que involucran las clases de lectura en la enseñanza media de las escuelas de educación básica en Brasil, enfocándose en la producción de lectura y cómo, frente a las políticas brasileñas sobre la formación docente, los profesores continúan presentando una pedagogía de la lectura que es obsoleta ante las demandas sociales y no alcanza las expectativas de los textos del Gobierno Federal sobre la formación para el letramento. El recorrido de construcción del texto consideró un breve recuento histórico, en el que se historiza la relación que la escuela viene manteniendo con la lectura, a través de evidencias documentales y literarias, culminando con datos empíricos de investigación realizada en una escuela de enseñanza media de la capital baiana en el momento en que el libro didáctico es implantado en la enseñanza media. Así, se trajeron testimonios de docentes y discentes relatando sus experiencias con la enseñanza aprendizaje de lectura en la escuela. Los resultados apuntan que, aunque ha habido una mejora en los resultados de evaluaciones externas con relación a la lectura, mucho esfuerzo aún necesitará ser dispensado para que la formación del lector considere la autonomía, la situacionalidad y la intercricidad, adjetivos considerados primordiales para la constitución de sujetos de lectura.

Palabras Clave: Lectura. Políticas Educativas. Formación Docente. Alfabetización. Educación.

\section{plurais}




\section{READING AND TEACHING WORK IN SCHOOL: yesterday and today}

This article aims to provoke a discussion about the pedagogical actions that involve reading classes in high school of basic education schools in Brazil. It is focusing on the reading production, and how, in front of the Brazilian policies on teacher training, teachers continue to show a obsolete reading pedagogy in the face of social demands and does not reach the expectations of the texts of the Federal Government on training for literacy. The route of the construction of this text considered a brief historical overview, in which Historicizing the relationship the school has maintained with reading through documentary and literary evidence, culminating with empirical research data held in a high school in Salvador/Bahia at the time the textbook is deployed in high school. Thus, teachers and students were brought testimonials about their experiences with the reading teaching and learning at school. The results shows that although there has been an improvement in the results of external evaluations in relation to reading, much effort will still need to be released so that the reader's training consider autonomy, situatedness and intercriticality, adjectives considered overriding for the development of reading's subjects..

Keywords: Reading. Educational Policies. Teacher Training. Literacy. Education. 


\title{
LEITURA E TRABALHO DOCENTE NA ESCOLA: ontem e hoje
}

\author{
LDBEN nº394/96, Art. 35. O ensino médio, etapa final da educação básica, \\ com duração mínima de três anos, terá como finalidades: \\ I - a consolidação e o aprofundamento dos conhecimentos adquiridos no ensino \\ fundamental, possibilitando o prosseguimento de estudos; \\ II - a preparação básica para o trabalho e a cidadania do educando, para \\ continuar aprendendo, de modo a ser capaz de se adaptar com flexibilidade a \\ novas condições de ocupação ou aperfeiçoamento posteriores; \\ III - o aprimoramento do educando como pessoa humana, incluindo a formação \\ ética e o desenvolvimento da autonomia intelectual e do pensamento crítico; \\ IV - a compreensão dos fundamentos científico-tecnológicos dos processos \\ produtivos, relacionando a teoria com a prática, no ensino de cada disciplina.
}

Originalmente voltado para a formação profissional, seja preparando para o ensino superior, seja profissionalizando, o Ensino Médio (EM), nos anos 1960 a 1980, servia a um mundo do trabalho de estrutura taylorista-fordista própria das linhas de montagem (MAFRA, 2003), isso, porque, naquele momento, havia uma dualidade: o educando optava por fazer um curso profissionalizante ou continuar os estudos preparatórios para os exames vestibulares. Naquele cenário, considerando o grande desenvolvimento da industrialização no Brasil, a política educacional vigente priorizou a formação, no EM, de profissionais capazes de utilizar maquinarias e dirigir processos de produção. Hoje, as relações de trabalho têm mudado e as consequências dessas mudanças podem ser percebidas na preocupação de órgãos internacionais, e de cada nação de per si, em investir numa educação que atenda ao novo mercado, cumprindo o que versa a Lei de Diretrizes e Bases da Educação Nacional (LDBEN), um mercado regido pelas novas tecnologias que exigem uma formação não de acúmulo de conhecimento, mas de "capacidade de pesquisar, buscar informações, analisá-las e selecioná-las, capacidade de aprender, criar, formular, ao invés do simples exercício de memorização" (BRASIL, 2002, p.16), ou seja, utilizar os conhecimentos de forma autônoma e criativa.

Uma das primeiras medidas governamentais, no sentido de adaptar-se a essa nova necessidade do mercado de trabalho, foi tomada a partir da LDBEN - Lei $\mathrm{n}^{\circ} 9.394 / 96$, inserindo, pela primeira vez na história da educação no Brasil, o EM na educação básica, conforme vimos na epígrafe, a lei obedece ao exposto na Constituição de 1988 que já pronunciava essa concepção, quando, no

\footnotetext{
plupais 
inciso II do Art. 208, garantia como dever do Estado a progressiva extensão da obrigatoriedade e gratuidade ao ensino médio. Assim, o EM passou a preparar não só para o mercado de trabalho, o que provocou o fechamento da maioria dos cursos profissionalizantes, mas para a continuação dos estudos, tornando o EM propedêutico, visando prioritariamente a formação em nível superior, universitária. No entanto, essa concepção, atualmente, está sendo objeto de revisão, através dos decretos 2.208/97 e 5.154 que trazem o conceito de ensino médio integrado (BAHIA, 2006), uma vez que a formação em nível superior não supre a necessidade do mercado de trabalho de mão de obra técnica qualificada.

Os Parâmetros Curriculares Nacionais para o Ensino Médio (PCNEM), embora sejam alvo de críticas, por, principalmente, apresentar-se como um documento prescritivo e que dispensou a participação dos profissionais que atuam em sala de aula, será trazido para discussão porque todas as ações avaliativas e de interferência pedagógica na escola pública fazem referência ou alusão a esse documento. Nele, a linguagem é considerada "como a capacidade humana de articular significados coletivos e compartilhá-los" (BRASIL, 2002, p. 05) e toma uma dimensão transdisciplinar, tendo papel importante na nova abordagem pedagógica proposta pela reformulação da LDBEN, a qual visa desenvolver competências e habilidades que forneçam aos jovens egressos do EM "meios para progredir no trabalho e nos estudos" (Art.22, Lei nº. 9.394/96).

Inserida nesse contexto, a leitura tem se constituído, nas últimas décadas, uma preocupação como componente na formação educacional dos jovens egressos do EM e muitas pesquisas têm sido feitas a esse respeito. Isso porque avaliações internas e externas ao ambiente escolar, promovidas pelo Governo Federal, têm apontado para uma deficiência na competência leitora dos jovens egressos do EM, seja na forma do Programa Internacional de Avaliação dos Estudantes (PISA), um programa da Organização para Cooperação e Desenvolvimento Econômico (OCDE), organização não governamental originária da União Européia, cujo objetivo declarado é auxiliar os governos-membros no desenvolvimento de melhores políticas nas áreas econômicas e sociais, a qual trienalmente avalia os alunos na faixa dos 15 anos, idade em que se pressupõe o término da escolaridade básica obrigatória na maioria dos países participantes desse projeto; seja do Sistema de Avaliação do Ensino Básico (SAEB). Nascido no âmbito das discussões internacionais, surgidas no final da década de 1980, sobre a qualidade de ensino, através de pesquisa desenvolvida pelo Instituto Internacional de Avaliação da Educação, com sede na Holanda (embrião do PISA). 
Conforme estudo desenvolvido por Batista e Rojo (2003) sabe-se que esses programas são sistemas de avaliação que visam medir os resultados do ensino básico em termos de construção de capacidades e competências, conforme evidenciado no site oficial do Inep:

O objetivo do Pisa é produzir indicadores que contribuam para a discussão da qualidade da educação nos países participantes, de modo a subsidiar políticas de melhoria do ensino básico. A avaliação procura verificar até que ponto as escolas de cada país participante estão preparando seus jovens para exercer o papel de cidadãos na sociedade contemporânea. (http://portal.inep.gov.br/pisaprograma-internacional-de-avaliacao-de-alunos Acesso em 25ago2014)

Conforme percebe-se no objetivo declarado acima, esses tipos de avaliações têm o objetivo de transformar a escola em empresa, sob a inspiração do programa de qualidade total no trabalho, inclusive prevendo locação de maiores recursos para os estabelecimentos escolares que tiverem melhores resultados, estabelecendo um ranking. Embora a teoria traga uma proposta de avaliação do desempenho escolar, na prática, o que se percebe é que esse ranking tira muito seu caráter educativo.

De qualquer modo, os resultados, de um modo geral, têm apontado para problemas nas capacidades e competências leitoras dos jovens brasileiros. Embora os últimos resultados apontem para aumento das notas, elas ainda não refletem uma situação de leitura muito confortável, colocando o Brasil em $55^{\circ}$ lugar entre os 65 países participantes, conforme site oficial do Inep. Isto significa dizer, à luz das concepções norteadoras de tais programas que,

Algumas atividades nesse nível requerem ao leitor localizar uma ou mais informações, que podem precisar de inferências e de condições variadas. Outras requerem reconhecer a ideia central de um texto, compreender relações ou construir significados dentro de um fragmento limitado do texto quando a informação não é evidente e o leitor deve realizar pequenas inferências. Atividades nesse nível podem incluir comparações ou contrastes baseados em um único elemento do texto. Atividades típicas de reflexão neste nível exigem que os leitores realizem comparações ou várias conexões entre o texto e seus conhecimentos, obtidos pela experiência pessoal ou atitudes. ${ }^{1}$

Por esse motivo, a leitura tem se tornado uma preocupação constante tanto nos meios acadêmicos, quanto nos órgãos de educação do governo brasileiro. Para entender um

$1 \mathrm{http}$ //download.inep.gov.br/acoes_internacionais/pisa/marcos_referenciais/2013/matriz_avaliacao_leitura.pdf Acesso em 25 ago 2014.

plurais 
pouco o que acontece hoje, nas escolas, no que tange à leitura, vejamos, a princípio, o que nos diz a história, depois o que os documentos oficiais falam sobre isso. Permeando estes discursos, teremos os depoimentos recolhidos em pesquisa de mestrado (CAMPINHO 2008).

Orlandi (1997) defende que significar é da ordem do humano, constituindo-o. Para essa autora, há uma injunção à interpretação, ou seja, tudo tem de fazer sentido, seja ele qualquer que seja, pois o homem se constitui através de sua relação com o simbólico. Sendo assim, o simbólico de que é constituída a linguagem, é inerente ao ser humano e, por isso, só sabemos ser pela linguagem. A leitura, sendo constituída de símbolos, representação simbólica de seres humanos no mundo, faz parte de nosso dia-a-dia de forma tão intensa que acabamos acreditando ser algo natural e que não necessitaria de qualquer problematização ou reflexão. Assim, tendemos a pensar que formar leitores é fazer com que nossos alunos e alunas sejam capazes de ler e ponto. E por muito tempo, a escola se ancorou nessa ideia. Essa certeza, porém, deixa de existir ao se observar o que outros professores fizeram em outros momentos da história do ensino da leitura. Nesse caso, percebe-se que não se entendia a formação de leitores do mesmo modo que se entende hoje, pois as finalidades que hoje são atribuídas ao ensino da leitura eram diferentes e, muitas vezes, quando adotamos certas práticas e metodologias para o aprendizado da leitura, damos continuidade a antigas concepções de formação de leitores, com as quais usualmente discordamos.

No final do século XIX e no início de XX, a expansão da escolarização, no Brasil, deu-se gradativamente, tornando-se uma das metas do governo republicano, instalado em 1899. Várias reformas de ensino começaram a ser propostas e novos métodos e teorias educacionais passaram a ser difundidos. Apesar dessas iniciativas, muitas vezes a escola, em seu cotidiano, continuava muito semelhante ao que havia sido para as gerações anteriores: espaços mal iluminados, mobiliário precário, professores mal remunerados e, muitas vezes, improvisados faziam parte do coti- 
diano escolar. Um cenário ainda presente em várias escolas brasileiras, a despeito das políticas de formação em serviço implantadas pelo Governo Federal a partir da década de 90 do século XX.

Naquela época, os castigos físicos norteavam a ação escolar e estudantes, todos na mesma sala, eram agrupados pelo nível de instrução que possuíam. Essa medida era dada pelo livro didático (LD), através do nível de leitura em que cada um se encontrava. O professor não dava aulas, como hoje estamos acostumados a pensar, mas tomava a lição de cada um dos alunos, fazendo-os ler em voz alta. O processo de tomar a lição consistia em o docente escolher e indicar antecipadamente um trecho de um texto para que o discente fizesse a leitura em voz alta diante da turma. Portanto a leitura, parece, estava ligada à decodificação do código vocabular, à fonética e prosódia. Aprendia-se a ler, na escola, para mostrar essa leitura em público.

A oferta de leitura na escola era muito restrita, geralmente ligada ao LD, o qual trazia, modo geral, apenas textos canônicos, de autores já mortos e, inicialmente, na sua maioria, de autores portugueses. Os objetos disponíveis para a leitura, não só na escola, mas nas diversas instâncias sociais, eram raros e poucos eram os lugares onde se podiam adquirir esses objetos, pois bibliotecas e livrarias só existiam nas cidades mais populosas. Por conta disso e aliado ao fato de poucas pessoas frequentarem a escola, havia poucos leitores.

Graciliano Ramos, em Infância, narrativa autobiográfica de sua meninice na virada do século XIX para o século XX, conta que sentia dificuldades para entender as lições, e o livro da escola chegava a lhe provocar náuseas. As horas de leitura eram, para o menino, horas de tortura. O mesmo menino que, depois de entrar em contato com algumas obras literárias fora da escola, passou a buscar com ânsia e prazer outros objetos de leitura na pequena cidade em que morava, no sertão pernambucano. Havia se tornado leitor, a despeito das práticas escolares, simplesmente por ter acesso aos livros.

Provavelmente a leitura tenha provocado náuseas no pequeno Graciliano por ter uma linguagem fora de seu tempo, pois é tradição entre os compêndios, transcrever os textos conforme os autores o escreveram em seu tempo, muitas vezes tão atemporal que torna a "linguagem mais complexa e a leitura difícil" conforme chama atenção um estudante do ensino médio, em depoimento colhido para compor corpus de trabalho de pesquisa de mestrado (CAMPINHO, 2008). Sobre isso, observa-se que nos livros do EM, por exemplo, é comum o trabalho com textos da poesia

\section{plurais


trovadoresca, do Barroco e do Arcadismo, todos esses com a linguagem de época preservada. Independente de entrar na recente discussão acerca da tradução de textos clássicos para a linguagem atual, esses textos eram escritos em uma língua que ainda não havia sofrido as regulações que ocorreram a partir do século XVIII, daí um estranhamento bem maior.

José Lins do Rego, em Doidinho, romance autobiográfico que narra sua vivência em um internato no início do século, registra momentos de angústia ao ler para o seu professor as lições do livro escolar. Mas, apesar do sofrimento que marcou, no geral, a sua relação com os objetos de leitura escolares, o futuro escritor confessa a ampliação de horizontes proporcionada por eles, fazendo-o conhecer outros mundos e a relativizar o seu. Em alguns casos, a leitura também provocava prazer, apesar das práticas escolares não terem essa intenção e, de modo geral, a relação entre leitura e prazer ser vista como danosa.

As oportunidades de leitura escolares tinham em vista formar leitores não propriamente para desenvolver as competências e usos da leitura, mas antes, provavelmente, o que se buscava na formação de leitores era a transmissão de conteúdos instrutivos, em geografia, história, ciências e habilidades básicas de leitura e escrita e das regras ortográficas do Português, além da transmissão de regras e modelos de comportamento vigentes na época.

Aos poucos, a sociedade começou a se tornar mais complexa e as demandas em torno da escolarização aumentaram significativamente. Entre as décadas de 1920 e 1950 mais postos de trabalho surgiram, outros costumes culturais foram adotados: a instrução e a educação passaram a ser vistas como necessárias ao desenvolvimento econômico e cultural do país e um dos signos da civilidade. Nesse novo cenário, várias reformas de ensino foram empreendidas, tentando mudar o triste marco de o Brasil chegar ao século XX com mais de $80 \%$ da população analfabeta. Durante as reformas, a rede pública de ensino expandiu-se enormemente. Novos métodos de ensino foram discutidos no país, sob a forte influência do movimento da Escola Nova. Novos modos de ler e inovadores papéis passaram a ser atribuídos à leitura na escola. A leitura silenciosa, por exemplo, passou a ser prescrita não só na escola, mas em outras instâncias da sociedade e a cada dia lia-se menos coletiva e oralmente.

Com a progressiva introdução da leitura silenciosa e rápida, da busca do significado do texto, em detrimento da memorização do texto e de seus conteúdos, antes valorizados, com o progressivo

\section{plurais}


abandono da doutrinação moral e ideológica e a progressiva introdução de novos gêneros de textos e de impressos nas salas de aula, essas práticas e objetos de leitura restritos foram gradualmente sendo ampliados. No entanto, o que se via era ainda uma canonização do texto e do autor, "uma concepção de língua como representação do pensamento e de sujeito como senhor absoluto de suas ações e de seu dizer, o texto é visto como um produto - lógico - do pensamento do autor (...)" (KOCH, 2003, p. 16). Essa concepção preconiza um leitor passivo ao qual cabe captar a representação mental, juntamente com as intenções do produtor do texto.

O saldo positivo, até aqui, é que o público leitor cresceu e se diversificou. Mas, apesar de todo esse movimento na produção intelectual sobre a leitura escolar, o dia-a-dia da maioria das escolas continuava sem muitas inovações: os alunos continuavam temerosos em ler as lições, ainda tomadas em voz alta, e a angústia e o tédio continuavam a marcar a sua relação com a leitura prescrita pela escola.

Em muitas escolas, alguns objetos de leitura chegaram a ser proibidos - como as histórias em quadrinhos, que fascinaram crianças e jovens dos anos 1930 e 1940. No entanto, a despeito da proibição, da censura, havia - e ainda hoje há - uma grande circulação de objetos de leitura entre os alunos, independente do que a escola prescreve.

Entre as décadas de 1950 e 1970, cada vez mais se desenvolviam métodos alternativos de ensino: surgiram as escolas experimentais e a ideia de um ensino centrado no aluno e nas suas necessidades. A rede pública de ensino se expandia de modo muito rápido: cada vez mais as camadas populares ingressavam na escola. Porém, muitas escolas continuaram a adotar antigos comportamentos e métodos, tornando desagradáveis e temidos os momentos em que as práticas de leitura se davam. Nesse período, aumentaram também os meios de acesso à leitura: bibliotecas populares, inclusive ambulantes, foram criadas em muitas cidades do país e o número de livrarias também aumentou significativamente.

A partir década de 1970, há uma necessidade de atualização do conteúdo, cada vez mais rápida, por conta do desenvolvimento de pesquisas que modificam o conhecimento pedagógico e do ritmo da vida social que se modificou muito com a popularização da mídia jornalística pela televisão. Com uma produção cada vez maior e mais diversificada, as obras destinadas aos leitores 
e leitoras infanto-juvenis passam a fazer parte, ao lado dos livros de leitura, das atividades de leitura escolar: esse tipo de literatura também se escolariza. A escolarização do texto é aqui entendida como o controle exercido pela escola sobre o que e como se deve ler. Nesse sentido, o texto sai de seu contexto de circulação e se presta a objetivos meramente didáticos, desconsiderando-se sua estética e características de gênero.

Mais recentemente, e a cada dia de maneira mais intensa, procura-se tornar presentes, nas escolas, os usos sociais da língua escrita, na diversidade dos modos de ler e na diversidade dos gêneros e dos portadores ou suportes de textos. O livro didático é colocado em xeque pelo emprego do jornal, do livro, da revista e de todo um conjunto de textos cuja presença era proibida na escola: quadrinhos, rótulos, listas, quadros e tabelas, placas, publicidade. Ao lado disso, livros e artigos têm surgido, buscando auxiliar as professoras na tarefa de tornar seus alunos e alunas, leitores e leitoras. Cada vez mais fala-se na alegria de ler, no prazer provocado pela leitura.

Estudos e pesquisas que procuram analisar o cotidiano da escola - em seu passado e em seu presente - mostram que, a despeito de todos esses fatores de mudança e transformação, as práticas escolares ainda hoje tendem a restringir fortemente a oferta de leitura e a formação de leitores. Esses estudos indicam que os professores e as professoras - mesmo numa época de diversificação da produção editorial brasileira - tendem a selecionar textos que evidenciem uma forte preocupação com a formação moral e ideológica de seus alunos ou com o aprendizado das regras de correspondência entre letra e fonema e de ortografia, usando o texto como pretexto. Esses mesmos estudos mostram também que muitas professoras orientam seus alunos a lerem os textos, buscando, ao final de sua leitura, descobrir qual teria sido a lição da história, seu principal ensinamento ou exemplo, evidenciando uma concepção de língua e linguagem como código transparente e possuidor de uma interpretação única que é a correta, entendendo interpretação como sinônimo de leitura. Por fim, esses estudos mostram que o prazer da leitura é algo ainda muito distante da maior parte das escolas e que os alunos tendem a ver suas aulas de leitura de maneira não muito diferente da de Graciliano Ramos: "horas de tortura e aborrecimento"(RAMOS, 1981,p. 155).

Na virada do século XX para o século XXI, vários documentos produzidos sob orientação do Governo brasileiro estabeleceram diretrizes sobre o fazer pedagógico referente à língua e à linguagem, trazendo uma concepção interacional de leitura, na qual o texto é considerado um 
lugar de trocas e o autor e leitor passam a ser interlocutores que se constituem e são constituídos no ato de ler. Nessa perspectiva, a leitura é uma atividade interativa e de construção de sentidos na interação texto-sujeitos. Portanto, as orientações para a aula de leitura, atualmente, preconizam o desenvolvimento da autonomia intelectual e do pensamento crítico e, para isso, é necessário que o leitor interaja com o texto, sendo autônomo, intercrítico e situacionado (OLIVEIRA, 2015).

Esses adjetivos: autônomo, intercrítico e situacionado, sendo ligados à situação de leitura são, segundo Oliveira (2015), inerentes a uma pedagogia do enleituramento a qual visa a formação cidadã através de textos que circulam socialmente, ampliando conhecimento de mundo e de gêneros textuais, colaborando para que o leitor perceba nuances implícitas na tecitura textual que fará com que se torne cidadão intercrítico, ou seja, o que considera as possibilidades, não anulando o outro, como nos ensina Macedo (2010), autônomo, o qual, em Freire (2009), é processo de elaboração/ criação constante de práticas e situacionado, no sentido atribuído a essa palavra a Análise de Discurso, entendendo que o contexto interfere na compreensão do sujeito, mas não é determinante, no sentido do determinismo ideológico do início do século XX. Enfim, torne-se leitor autônomo, intercrítico e situacionado, adjetivos inerentes à ideia de letramento, a qual vamos nominar neste texto, por falta de vocábulo melhor, leitura pedagógica.

Para um melhor entendimento das considerações feitas doravante, faz-se necessário estabelecer definições sobre leitura individual e leitura pedagógica. Por falta de uma designação mais adequada, tomaremos a definição de leitura pedagógica, aquela que é conduzida pedagogicamente no ambiente escolar, pois cabe principalmente à escola desenvolver as capacidades e habilidades concernentes à produção de leitura, à formação do leitor crítico e independente. Já a leitura individual é aquela em que o leitor interage com a leitura por razões outras que não as pedagógicas do ambiente escolar. A leitura pedagógica é tomada, aqui, como produção de leitura, ou seja, observação, análise, reflexão, planificação, tomada de decisão e, finalmente, ação. Ela costuma ser concebida em dois estágios: leitura decifratória, ou de decodificação, aquela em que a atenção e o esforço do leitor se dissipam principalmente na decifração, no esforço de decodificar o código escrito e a leitura crítica, em que se emprega pequeno esforço na decifração e que supõe um leitor crítico. Ambas as leituras visam - ou deveriam visar - o letramento, que faz do leitor um agente ativo do que lê.

\footnotetext{
plupais 
Nas práticas de sala de aula, atualmente, percebem-se situações diversas como as descritas por alunos em entrevistas colhidas em setembro de 2005 para compor o corpus de trabalho de pesquisa de Campinho (2008). Nesse trabalho, foram ouvidas professoras de Língua Portuguesa de uma escola pública de ensino médio, situada no centro da Capital baiana, no sentido de saber a sua opinião sobre o uso do livro didático distribuído pelo Governo Federal, introduzido pela primeira vez no ensino médio brasileiro. Além disso, foram ouvidos também estudantes desses docentes, no sentido de perceber como era feita a aula de leitura por esses profissionais. Os relatos dos sujeitos da referida pesquisa são trazidos abaixo em alguns momentos, tendo sido preservada a sua identidade, sendo identificados por PROFESSOR ou ALUNO.

Ela chega, ela senta, aí faz tipo uma... coloca os alunos ao redor dela, aí lê e manda as outras pessoas lerem, entendeu? Aí os assuntos que ela passa de dever de casa, não coloca no caderno não, que ela não cobra a gente no caderno, ela responde, entendeu? Ela mesma vai falando e respondendo, tudo com a gente. É esse o trabalho dela (ALUNO 6).

Tanto nesse depoimento em particular como em outros colhidos nessa mesma turma, nota-se a falta de referência a um trabalho pedagógico voltado para a produção de leitura que vise a um leitor intercrítico, autônomo e situacionado, conforme descrito acima. A leitura explorada pela professora parece ser a decifratória, de decodificação do signo linguístico o que não cabe a uma turma de EM e se distancia do que preconizam os documentos oficiais que regulam a educação brasileira. $\mathrm{O}$ texto entra no planejamento da aula sem considerar a sua textualidade, possibilidade de análise, de reflexão, de planificação, o que em nada contribui para a formação de um leitor cidadão.

Ela sempre bota a gente pra ler, quer dizer, quem quiser ler, né. mas ela sempre bota a gente pra ler. fala as páginas que é pra ler, se a gente quiser ler a gente lê, e assim... explica tudo, os pontos parágrafos, coisa assim que é pra gente ler, coisa assim (ALUNO 8)

Mais uma vez, temos um exemplo de concepção de leitura decifratória com uma informação a mais: pode-se inferir que a professora desse estudante demonstra que se preocupa com outros aspectos de leitura como postura, prosódia, uma vez que pede para que os alunos leiam. No entanto, é importante considerar que esse tipo de leitura está muito aquém do que se espera de alunos egressos do ensino fundamental. Pelo depoimento, observa-se que uma leitura pedagógica de atribuição de sentidos ao texto, de desenvolvimento de habilidades de análise, observação, reflexão, enfim, desenvolvimento de senso crítico e formação de cidadão não fazem parte da prioridade dessa aula, 
pois a professora "explica tudo" e o tudo que ela ensina está mais ligado à prescrição gramatical que ao uso prático da linguagem. $\mathrm{O}$ mesmo não se percebe neste outro depoimento:

a professora passa os textos, né, ela discute muito com a gente, deixa tudo bem claro na nossa mente, é super bom mesmo, reforça mesmo a nossa leitura, assim quem tem preguiça de ler (risos) aí vai lendo... eu gosto dos textos também, é fácil (ALUNO 10)

Pode-se inferir que essa professora promove um trabalho que leva à leitura crítica, através de debate sobre o texto com seus alunos, promovendo reflexão, tentando favorecer um ambiente para o desenvolvimento de habilidades de leitura crítica. O que é mais condizente com um trabalho voltado para o EM, mas que ainda está aquém do esperado para esse ciclo escolar, o qual, segundo orienta a matriz de avaliação de leitura do PISA/INEP, deveria ser:

realização de múltiplas inferências, comparações e contrastes com precisão e detalhamento, demonstrando uma compreensão completa e detalhada de um ou mais textos que podem envolver integração de informação entre esses, lidando com ideias desconhecidas, na presença de informações concorrentes, gerando categorias abstratas de interpretação (BRASIL, 2001, p. s.n.).

As atividades de Refletir e Avaliar requerem que o leitor delineie hipóteses ou que avalie de forma crítica um texto complexo ou tópico desconhecido, levando em consideração múltiplos critérios e perspectivas, e aplicando interpretações sofisticadas para além do texto. Uma condição presente para exercícios de acessar e recuperar nesse nível é a precisão de análise e atenção refinada para encontrar detalhes pouco perceptíveis nos textos. Mas esses procedimentos não foram encontrados na pesquisa acima apontada.

Nos depoimentos acima, com alunos de diferentes professoras, podemos perceber quão diversificado é o trabalho de leitura na escola. Enquanto alguns estão ainda presos à decodificação e textos canônicos, notadamente os dois primeiros, outros já trazem textos do cotidiano e provocam inferências, análises, uma leitura que leva à reflexão e autonomia, embora ainda longe do que se espera para um egresso do ensino fundamental.

A despeito de toda a preocupação relativa à leitura, visível através de projetos incentivados e subsidiados por instâncias governamentais, pouco se sabe sobre que tipo 
de leitura é feita na escola. Que concepção de leitura as professoras têm? Nos depoimentos colhidos entre professoras e alunos, foi percebida uma incongruência entre o que a professora diz que faz e entre o que os alunos e as alunas dizem que a professora faz, ressaltando, nessa desavença, uma concepção de leitura que versa em sentido diferente daquelas preconizadas pelas políticas públicas de educação no nosso país. As quais dizem que:

As competências e habilidades propostas pelos Parâmetros Curriculares Nacionais para o Ensino Médio (PCNEM) permitem inferir que o ensino de Língua Portuguesa, hoje, busca desenvolver no aluno seu potencial crítico, sua percepção das múltiplas possibilidades de expressão linguística, sua capacitação como leitor efetivo dos mais diversos textos representativos de nossa cultura. Para além da memorização mecânica de regras gramaticais ou das características de determinado movimento literário, o aluno deve ter meios para ampliar e articular conhecimentos e competências que possam ser mobilizadas nas inúmeras situações de uso da língua com que se depara, na família, entre amigos, na escola, no mundo do trabalho (BRASIL, 2002, p. 55)

Portanto, podemos dizer que as orientações governamentais versam sobre um leitor autônomo, intercrítico e situacionado, capaz de atribuir sentidos aos textos e de dialogar com eles de forma crítica, conforme já explicitado anteriormente. Dessa forma, tais orientações determinam uma concepção de texto que, por conta de uma formação docente nem sempre guiada por uma lógica do letramento; por conta da situação social do docente, situação global do discente, entre outros tantos tangíveis e intangíveis fatores, está longe daquela praticada pelas professoras e impõem um fazer em sala de aula para o qual docentes talvez não estejam preparados. No entanto, nota-se o silenciamento de docentes diante do dizer acadêmico institucionalizado através do discurso da autoridade, reorganizando o seu dizer para se aproximar do desejável pelas autoridades:

PROFESSORA 1: (...) você sabe que leitura e escrita são interligadas: não adianta apenas saber ler. Tem que haver criticidade ao ver o mundo, o seu mundo, o mundo lá fora, relacionar, entender os problemas e também ler por prazer, então como trabalhar esse prazer? $\mathrm{O}$ aluno hoje em dia, com a competição, com a internet, com a coisa fácil, não têm o prazer do livro, preferem até ler livros, quem tem acesso, através dos computadores. Então eu pergunto: será que poderão levar esses livros em ônibus pra ler ou em momentos vagos? 
Nesse depoimento, ainda parte da pesquisa anteriormente mencionada, nota-se um discurso em defesa do livro, como se a leitura fosse apenas a da literatura, uma ideia, por sinal, que faz parte da cultura escolar e já é tradição ali, conforme vimos no histórico feito anteriormente. A professora relaciona a ideia de criticidade, o "ver o mundo, o seu mundo lá fora" com o livro. Num mudo tão globalizado, a leitura escolar não pode se restringir e não se restringe ao livro, é necessário fazer a leitura de textos do cotidiano: físicos e virtuais.

Na pesquisa de Campinho (2008), ainda há um outro sujeito de pesquisa que aparece de forma muito importante, pois posiciona-se como observador quase apagado da cena sala de aula, por ser estudante de graduação em situação de estágio. Esses sujeitos, por vezes fazem registro de que os alunos têm dificuldade em ler, no sentido de decodificar o escrito, outras há em que a dificuldade reside em atribuir sentidos ao texto. Nesse caso, em particular, foi notada a dificuldade em decodificar a linguagem usada no texto, pois esse se insere na escola romântica, tão longe da realidade linguística atual, tão longe da realidade cotidiana do aluno, sem conhecimento prévio de tal estilo de linguagem.

Uma estagiária que participou da referida pesquisa relata a seguinte fala de um aluno, após a leitura feita com dificuldade por ele: "É difícil ler poesias como esta, porque as pessoas da época eram muito inteligentes". Pode-se perceber, nessa fala, a forte influência de uma ideologia imposta às classes mais baixas da sociedade de que os seus conhecimentos são desprezíveis e de que há um modelo de inteligência associada aos cânones. A observadora relata que a professora contestou a fala de seu aluno e debateu o assunto, um procedimento que aponta para um modo de ver o ensino-aprendizagem na sala de aula que valorize o diálogo, o debate, a construção do conhecimento, considerando os dois sujeitos nesse processo: aquele que aprende ao ensinar e o que ensina ao aprender, conforme nos ensinou Freire (1996, p. 23), porém não há referência sobre uma interpretação do texto que leve à crítica social, ao diálogo do leitor com o texto, produzindo leitura e atribuição de sentidos. Sendo assim, percebemos que, de modo geral, as professoras têm explicitada a ideia da leitura que extrapola a decifração do código, que preconiza um leitor autônomo, um leitor de mundo:

PROFESSORA 3: O mais importante para mim é o trabalho com leitura, interpretação e produção de textos, pois através do domínio dessas habilidades o indivíduo se torna capaz de fazer uma leitura do mundo de forma eficiente, além de construir o seu conhecimento.

\footnotetext{
plupais 
PROFESSORA 4: A leitura era trabalhada através de textos extraídos de livros, jornais, revistas, etc. Os textos eram lidos, discutidos pelos grupos. Os próprios alunos elaboravam questões de interpretação que eram apresentadas aos demais para a obtenção de respostas que levassem a vários questionamentos e culminassem com a conclusão do trabalho proposto. Em outros momentos, eram levados textos para que fossem pesquisadas palavras com o objetivo de enriquecer o vocabulário e as questões eram previamente elaboradas por mim, direcionando o trabalho a ser conduzido. Uma outra alternativa era a distribuição de textos para que cada grupo de alunos expressasse sua opinião acerca do assunto neles tratados para elaborar, posteriormente, seus próprios textos.

No entanto, o que se evidencia nos relatos dos alunos é uma prática destoante da realidade apresentada pelas professoras, na qual a leitura é parafrástica, ou seja, a que se caracteriza pelo reconhecimento (reprodução/ reformulação do sentido dado pelo texto-fonte) para a produção de um texto-derivado (ORLANDI, 2001) e/ou de decodificação. Para os alunos consultados, a concepção de leitura corresponde à decodificação do código gráfico, isto é, para eles ler é saber decifrar as palavras e os sinais gráficos, tanto as marcas de prosódia, quanto as marcas estilísticas de pausa e entonação, que as acompanham.

(...) a professora de português, o trabalho dela eu gosto, entendeu. É bom porque ela incentiva as pessoas a trabalhar junto, que ela incentiva as pessoas a ler, entendeu, na sala de aula, para tirar também a vergonha que as pessoa têm. (ALUNO 6)

(...) ela sempre bota a gente pra ler, quer dizer, quem quiser ler, ler, né. mas ela sempre bota a gente pra ler. Fala a página que é pra ler se a gente quiser ler a gente lê, e assim... explica tudo, os pontos parágrafo, coisa assim que é pra gente ler, coisa assim.(ALUNO 8)

Para efeitos de análise, podemos inferir que se o aluno não se reporta a um estudo de leitura que promova o diálogo e o pensamento crítico e divergente, é porque ele não existe. Em outros depoimentos, evidencia-se o silenciamento que, com relação ao texto, as professoras impõem aos seus alunos:

Ela chega, ela senta, aí coloca os alunos em redor dela, aí lê e manda as outras pessoas leem, entendeu? Aí os assuntos que ela passa de dever de casa, num coloca no caderno não, que ela não cobra a gente no caderno, ela responde, 
entendeu? Ela mesma vai falando e respondendo, tudo com a gente. É esse o trabalho dela. (ALUNO 6)

A professora não oferece possibilidades de promoção da autonomia, intercrítica e situcionalidade, tão importantes para a formação do cidadão atuante socialmente, pelo contrário, silencia outros sentidos atribuíveis à leitura quando "Ela mesma vai falando e respondendo". Além de silenciar a sua própria leitura ao engajar-se na leitura proposta no $\mathrm{LD}$, como podemos perceber na análise que seu aluno faz da aula:

Ela chega... pede boa noite, é claro, fala: "hoje vamos trabalhar com o Barroco, abra o livro em tal página", aí começa a leitura, ela explica, pergunta as dúvida da gente, se a gente tem dúvida em alguma coisa, explica... é isso (ALUNO 7)

Portanto, diante do exposto, podemos dizer que a leitura na escola caminha entre o que se diz, ou seja, o desejável perante as possibilidades que alunos egressos de, no mínimo, dez anos de aulas de leitura deveriam apresentar, ou o previsto entre as orientações governamentais e o que se faz, ou seja, o que a professora consegue desenvolver em sala de aula, levando em conta as suas próprias limitações e as limitações dos alunos e alunas. Assim, a produção de leitura não se consubstancia enquanto atividade visceral da aula de Língua Portuguesa.

Conforme o exposto, vimos uma tendência de apagamento da voz do professor, atrás de políticas paternalistas de apresentar normas e procedimentos, além do próprio planejamento da aula, através do LD. Geralmente as pesquisas desenvolvidas em ambiente escolar apontam para uma formação do docente que tem se apresentado equivocada e que não dá conta da formação do leitor intercrítico, autônomo e situacionado. No entanto, se esse é o problema que se aponta, por que não investir em reformas nos currículos de graduação, nos programas de formação continuada e num plano de carreira atraente, ao invés de investir num "amparo" através do LD? Uma possível leitura que se faz desses todos discursos é de descrença por esse profissional. Em AD discute-se que a prática científica não está segmentada da prática política e vice-versa. Ambas são determinadas pelas condições sócio-históricas e ideológicas de uma dada formação social. Nessa visão, o discurso dos cientistas da linguagem, que assinam as orientações governamentais, nada mais é do que o discurso do poder impondo metas e objetivos a serem alcançados, industrializando a escola, um espaço que deveria ser o da construção de conhecimento.

\footnotetext{
plupais 
Aos alunos, é reservado espaço ainda mais silencioso do que o do professor. Enquanto esse ainda é chamado para dar a sua opinião, àquele só resta calar e aceitar. Até na pesquisa de Campinho (2008) a voz do aluno é trazida de forma muito apagada, ainda que não seja objetivo da pesquisa feita tal discussão. A literatura ligada à crítica à educação é carente dessa análise. Orlandi (2001) adota a posição de que somos sujeitos simbólicos vivendo espaços histórico-sociais. Hall (2005) apresenta os estágios através dos quais uma versão particular do "sujeito humano" emergiu na idade moderna: a princípio como sujeito centrado, com um sentimento estável de sua própria identidade e lugar na ordem das coisas; seguido do sujeito sociológico, interativo, para uma concepção de descentramento do sujeito na modernidade tardia.

Trazendo essa perspectiva para o viés do estudo da Leitura e trabalho docente na escola: ontem e hoje, pode-se chegar às perguntas: A escola tem fomentado a formação do cidadão atuante socialmente? As aulas de leitura tem feito seu papel de ampliação de conhecimento de mundo? Por que o professor, a professora, em vários momentos, escolhe calar-se e repetir os discursos de outrem? Acreditamos que as respostas a essas perguntas podem ser buscadas nas cenas relatadas, bem como no seu contexto. Acreditamos, ainda, que proporcionar aos estudantes possibilidades de leitura autônoma, intercrítica e situacionada podem fazer com que a escola se torne mais atrativa aos jovens que verão ali o lugar de sua formação para o enfrentamento de situações diversas em sua vida pessoal, profissional e ecológica, conforme se espera da educação na atualidade.

Então, como exigir dos alunos a capacidade leitora de analisar, raciocinar e refletir ativamente sobre seus conhecimentos e experiências, enfocando competências que serão relevantes para suas vidas futuras, como propõem o PISA, ou que demonstrem habilidades de leitura de textos argumentativos mais complexos, relacionem tese e argumentos em textos longos, estabeleçam relação de causa e consequência, identifiquem efeitos de ironia ou humor em textos variados, efeitos de sentidos decorrentes do uso de uma palavra, expressão e da pontuação, além de reconhecerem marcas linguísticas do código de um grupo social como espera a Prova Brasil, se, em sala de aula, o estudo do texto não conduz à consecução desses objetivos? Se na escola os estudantes são levados a apagar a sua constituição leitora, pois é pouco requisitada? Se a voz do professor é apagada da cena político-educacional e esse profissional é alijado de atuar ativamente nas decisões que concernem ao ensino? 
Aos alunos da escola pública, sejam eles do ensino noturno ou do diurno, deve ser possível o desenvolvimento da cidadania e a constituição como sujeito ativo e crítico. Dessa forma, talvez, os resultados apresentados por programas tão amplos e centralizados de avaliação não apresentassem resultados tão aquém do esperado.

Repensar a estrutura em que se ancora a educação básica, através de amplos debates em que se ouvisse a voz dos professores, das professoras que efetivamente atuam em sala de aula, alunos e alunas, pais e demais segmentos da comunidade escolar seria bastante salutar. É preciso repensar as práticas pedagógicas e ideológicas, ligadas à educação dentro de cada comunidade escolar.

Por outro lado, não se pode deixar de enfatizar a importância no investimento nos profissionais da educação em suas formações iniciais e continuadas, da necessidade de se fazer um plano de carreira que valorize o profissional que procura sempre mais e mais conhecimentos para exercer seu trabalho, ou seja, docentes que se mobilizem no sentido de incentivar a autonomia, a intercrítica e a situcionalidade em seus estudantes. Além de se voltar para a pesquisa, como vem assinalando as reflexões feitas por Fiorin (2005), Moita Lopes (2006), André (2004), entre outros.

Muito de história poderíamos ter e quanto teríamos aprendido se, conforme orientação de Lopes e Cavalcanti (1991) a sala de aula tivesse sido um local não só de ensino, mas também de pesquisa. Certamente, teríamos agora um avanço tecnológico, educacional, didático, metodológico e humano, ainda, maior.

\section{REFERÊNCIAS}

BAHIA. SEC. Orientações curriculares para o Ensino Médio 2006. Disponível em http://portal.mec.gov.br/seb/arquivos/pdf/linguagens02.pdf. Acesso em 15 abr 2019

BATISTA, Antônio Augusto Gomes. ROJO, Roxane (Orgs). Livro didático de língua portuguesa, letramento e cultura escrita. Campinas, SP: Mercado de Letras, 2003.

BRASIL, MEC/INEP Relatório Nacional PISA 2000. Brasília, DF: dez. 2001.

BRASIL, MEC/SEMTEC. Parâmetros Curriculares Nacionais - Ensino Médio. Brasília, DF: 2002. 
CAMPINHO, Rosemary Lapa de Oliveira. A introdução do livro didático nas aulas de leitura no ensino médio da rede pública de ensino: um estudo de cunho etnográfico. Dissertação (mestrado) - Universidade Federal da Bahia, Instituto de Letras, 2008.

CAVALCANTI, Marilda C. LOPES, Luiz Paulo da Mota. Implementação de Pesquisa na Sala de Aula de Línguas no Contexto Brasileiro. In: Trabalhos em Linguística Aplicada. Campinas, n. 17 / jun 1991, p.133-144.

FIORIN. José Luiz. Formação do Profissional em Letras. Exposição oral do autor em aula inaugural do $1^{\circ}$ semestre letivo de 2005 da Faculdade de Letras da UFBA, cujo tema foi A reforma Universitária, realizada em 23 de março de 2005, UFBA-BA.

FREIRE, Paulo. Pedagogia da autonomia: saberes necessários à prática docente. São Paulo: Paz e Terra, 1996.

GOVERNO FEDERAL. MEC SAEB. Metodologia. Disponível em < http://www.inep.gov.br/ basica/saeb/metodologia/matrizes.htm Acesso em 20 jun 2005.

HALL, Stuart. A identidade cultural na pós-modernidade. Trad. Tomaz Tadeu da Silva, Guaracira Lopes Louro. 10 ed. Rio de Janeiro: DP\&A, 2005.

INEP. Resultados do SAEB 2003 Brasil e Bahia. Brasília - DF, junho 2004 http://www.fnde. gov.br/home/index.jsp?arquivo=/ld_ensinomedio/ld_ensinomedio.html

JURADO, Shirley G de O G. Leitura e letramento escolar no ensino médio: um Estudo exploratório. 2003. 150 p. Dissertação (Mestrado). Programa de Pós-Graduação em Linguística Aplicada. PUC-SP.

KOCH, Ingedore Villaça. A inter-ação pela linguagem. 8. ed. São Paulo: Contexto, 2003

KLEIMAN, Angela. Texto e Leitor: Aspectos Cognitivos da Leitura. 9. ed. Campinas, SP: Pontes, 2004

MAFRA, Núbio Delanne Ferraz. Leituras à Revelia da Escola. Londrina - PR: Eduel, 2003

MINISTÉRIO DA EDUCAÇÃO E CULTURA - FNDE. Disponível em http://www.fnde.gov. br/home/index.jsp?arquivo=/ld ensinomedio/ld ensinomedio.html Acesso em 22 nov. 2004.

MINISTÉRIO DA EDUCAÇÃO E CULTURA - FNDE. Disponível em www.fnde.gov.br. Acesso em 22 nov. 2004. 
MOITA LOPES, Luiz Paulo da (org.) Por uma linguística aplicada Indisciplinar. São Paulo: Parábola Editorial, 2006.

OLIVEIRA, Rosemary Lapa. A Pedagogia da Rebeldia e o Enleituramento: a constituição do sujeito leitor. Saarbrücken: Novas Edições Acadêmicas, 2015

ORLANDI, Eni Puccinelli. As formas do silêncio: no movimento dos sentidos. 4.ed. Campinas, SP: Editora da UNICAMP, 1997

ORLANDI, Eni Puccinelli. Discurso e Texto: Formulação e Circulação dos Sentidos. Campinas, SP: Pontes, 2001.

RAMOS, Graciliano. Infância. 23ed. São Paulo: Record, 1986.

REGO, José Lins do. Doidinho. 16ed. Rio de Janeiro: José Olympio, 1977.

Recebido em: 15 de abril de 2019.

Avaliado em: 20 de julho de 2019.

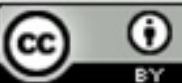

Esta obra está licenciada com uma Licença Creative Commons Atribuição 4.0 Internacional. 